\title{
Non-Diversifiable Risk in Investment Portfolios --- an Aid to Investment Decision Making
}

\author{
Emma Anyika \\ Department of Accounting and Finance, Mount Kenya P.O. Box 342-01000 Thika, Kenya \\ E-mail:mmnk55378@gmail.com
}

Received 1 January 2015

Accepted 5 February 2015

\begin{abstract}
Modeling Non - Diversifiable risk in investment portfolios is undertaken in this paper together with redefinition of estimators of diversifiable risk and portfolio expected returns to reflect normal market conditions. GARCH (General Auto - Regressive Conditional Heteroskedasticity) models are then used to make forecasts of given time series, from which future predictions of Non - Diversifiable risk, Diversifiable risk and portfolio expected returns are made. The required investment decisions are then made. In making investment decisions several factors are considered. These include profits, dividend yield, price earning ratios, and expected future performance of financial institutions. This paper has considered expected future performance of financial institutions. In particular the paper derives a method of determining non - diversifiable risk in investment portfolios that enables investors and investment managers make viable investment decisions. This study is expected to improve the accuracy of predicting future expected performance of financial institutions. Investment analysts can now rely on the predictions to make good investment decisions.
\end{abstract}

Non-diversifiable risk, Diversifiable risk, GARCH, portfolio

\section{Introduction}

Risk underlies most investment decisions. This is because it is not possible to anticipate the occurrence of possible future events with certainty and hence, making any correct predictions about the cash flow sequence is not possible. The simplest expression for risk in investment is the standard deviation of returns on investments. For single investments other risk determining expressions include coefficient of variation and the Beta (B) factor method, Wilkes (1996) and Value at Risk, Vlaar (2000). When dealing with investment portfolios, return on investment is a weighted average of the expected returns of the individual investment. This alone will not allow one to make investment decisions since one needs to determine the best portfolio by looking at that which will give maximum returns at the lowest risk. This necessitates determination of portfolio risk, which is divided into non-diversifiable and diversifiable risk.
Diversifiable risk is that which the investor can eliminate if he held an efficient portfolio. The nondiversifiable risk on the other hand is that risk which still exists in all well diversified efficient portfolios. The investor therefore seeks to eliminate the diversifiable risk. Nevertheless non-diversifiable risk permeates most areas of investment. These are particularly those characterized by unstable rates of returns due to the erratic nature of market forces. These include interest related portfolios and also exchange rates related ones. For new, short term, and long term players in investment markets there is need for proper determination of non diversifiable risk as a basis for investment decision making. This paper focuses on the problem of limited tools for estimation and prediction of non-diversifiable risk in investment portfolios that has lead to indecisiveness by investors and incorrect investment decisions. Non-diversifiable risk is not normally determined since most estimators present are 
used to determine diversifiable risk which can on the onset eliminate some risk by combining several investment portfolios until the best one is realized i.e. one with the highest returns at the lowest risk. Thus new and long-term investors who want to enter risky businesses, i.e. risk seekers, lack risk benchmarks on which to base their investment decisions. Many investors congest short-term investment markets believing that they have high returns and are less risky. This eventually brings down the earnings from these investments. For example short-term interest earning government bills and bonds will have their interest earning rates decreased if we have many investors in the market. Thus investors are left with only long term investments to consider. The situation could at least be made bearable if they knew precisely how much risk they are bound to encounter and how it will affect their rates of return.

The aim of this research was to determine a method of estimating non-diversifiable risk to enable investment managers make viable investment decisions. This estimator is that which accounts for the normal market conditions. This will decrease losses made by financial organizations due to inability to predict nondiversifiable risk accurately and reduce drastically the large provisions set aside to hedge and manage risk. The financial environment is full of risk hedging techniques and risk management measures for systematic risk. These are mostly done on speculative terms Jennifer (2003). There are no real concrete and long lasting solutions to the problems of non-diversifiable risk. Most financial market players blame it on the volatility of financial markets, i.e. that one cannot determine and predict non-diversifiable risk since the forces determining it keep on fluctuating.

The proper determination of non-diversifiable risk in this paper is expected to, prevent the making of wrong investment decisions by, for example, relying only on an investment managers belief or experience in risk management, boost the confidence of new, short - term and long-term investors since they would know the level of risk to be encountered. It would also enable investors have a broad spectrum of portfolios to invest in since most of them just engage in short term investments where non-diversifiable risk can be speculated easily, facilitate development of suitable risk managing and hedging techniques to minimize non- diversifiable risk and set free colossal amounts of money from elaborate schemes hatched to hedge and manage portfolio risk thus enabling reinvestment to improve or increase the profitability of financial organizations. The uncertainty of non-diversifiable risk, i.e., the fact that it is believed not to be exactly known Robert (1993), always makes investment markets so jittery such that any small force acting on these markets sends them tumbling. The proper determination of nondiversifiable risk will go a long way into stabilizing the investment markets.

Basic concepts applied include, diversifiable risk (also known as non -systematic or specific risk) which is the risk that can be eliminated by diversification. It is unique to the company or it's industry and includes management competence and shifts in demand for company products, non-Diversifiable risk (also known as systematic or market risk) which is related to fluctuation of the market as a whole and cannot be eliminated by diversification, Portfolio expected returns a weighted average of the expected returns of each asset held in isolation and Investment portfolio which is a combination of more than one investment with a belief that risk shared is risk less.

\section{Literature Review}

Originally portfolio expected return was the only criterion for making investment decisions. This has been lacking particularly in areas where the future of the expected returns was uncertain. Thus other methods which incorporated determination of future uncertainties have to be sought. Markowitz (1952) identified statistical measures of dispersion as measures of risk to be a way of indicating future uncertainties in investment decision making. Later on he modified his risk estimator to include correlation coefficient. This was significant since for example if investments are perfectly negatively correlated i.e. their correlation coefficient is negative one, and then holding them in a portfolio greatly reduces their risk. This is synonymous to the idea of not carrying all your eggs in one basket, i.e. in different baskets risk is shared thus less. Researchers then began to examine the implications of all investors using this approach.

This led to the development of the Capital Asset Pricing Model (CAPM), Sharpe, et al (1964), which 
gave a simple relationship between expected returns and risk in a competitive market. It also provided further insight into the process of diversification. Although there is a great deal of evidence which supports CAPM, there are major difficulties in testing the model. First it is stated in terms of investors' expectations rather than historic returns. Secondly the market portfolio (M) should include all risky investments, whereas most market indices contain only a sample of shares. Furthermore research in the 1980's mainly on U.S.A stocks revealed a number of stock market anomalies which are inconsistent with CAPM. These include "the small firm effect" and "calendar effects" Dimson (1988). The model should therefore not be relied upon for more than general indications of the market pricing mechanism. Currently, research in this area is centered on how to use the Markowitz estimator of risk and the CAPM in investment decision making. Less emphasis is being placed on further development of better risk estimators and models. Stulz (1999) argues that total risk is often costly and discusses how taking total risk into account in capital budgeting is necessary to make capital budgeting and capital structure decisions consistent. Harper (2003) discusses risk and returns in balanced portfolio and views the efficacy of cash and cash equivalents in investor portfolios. All the above researchers do not account for non-diversifiable risk as properly defined in their risk estimation thus rendering their estimators inaccurate. This paper seeks to remedy this by determining total risk which accounts for diversifiable and non-diversifiable risk according to its definition.

\subsection{Research methodology}

The population for this study was "Turnover of shares in Kenya shillings (Ksh) on the Nairobi Stock Exchange (NSE) from the year 2009 to 2013”. NSE is a Kenyan Capital Market. Currently there are fifty six financial institutions listed on the NSE. Every day the total turnover of shares in terms of volume and Ksh. is recorded for each one of the fifty six financial institutions. Each month a bulletin is released showing the ten or twenty leading companies in terms of turnover in Ksh. These companies differ from one period to another. Thus data from NSE is first analyzed.
Returns for shares are derived by taking a base month and the weighted average share price of an investment stock for that month and considering it as a buying price Subsequent share prices are taken as the selling prices and the returns are thus calculated. Simple random sampling is then used to pick the companies with the best returns over the five year period. This entails ranking the companies in terms of one with the highest turnover in Ksh for the five year period. It also involves ensuring that the companies selected are those that are making positive returns frequently. This is due to the fact that this study determines methods that will enable investors make the best investment decisions, thus picking a financial institution with the highest and most frequent positive returns is the first step towards making good investment decision.

Turnover from shares is derived by multiplying the weighted average share price per month by the turnover of shares in volume per month. Simple random sampling is then used to pick a number of companies from those with the highest turnover over the five year period. Assumptions made include the following; the sample data size is representative of the population, the values of weights range from negative infinity to positive infinity. It is important to note that the estimators derived and tested are used to predict future performance of certain financial institutions from the rest of the population. These estimators are expected to be used for prediction of future performance of financial institutions situated in any location, the only limitation to the use of the estimators being the accuracy of the forecasting techniques. S-Plus version 2000 and Mat lab version 6.1 software are used for mathematical and statistical calculations, problem solving, graphing and forecasting.

\section{Results}

\subsection{Derivation of True Functions of Diversifiable and Non-Diversifiable Risk}

Let the Markowitz portfolio expected returns and diversifiable variance be given by (1) and (2) respectively. See Andrew (1995) and Alexander (1974). 


$$
\begin{gathered}
E\left(R_{u}\right)=\sum_{i=1}^{\infty} x_{i} E\left(R_{i}\right) \\
P_{m}^{2}=\sum_{i=1}^{\infty} x_{i}^{2} \sigma_{i}^{2}+2 \sum_{i=1}^{\infty} \sum_{j}^{\infty} x_{i} x_{j} \sigma_{i j}
\end{gathered}
$$

Non-diversifiable variance is computed as

$$
P_{q}^{2}=\sum_{i=1}^{\infty} x_{i}^{2} \sigma_{i}^{2}
$$

where, $-\infty<x_{i}<\infty, 0<\sigma_{i}^{2}<\infty$, and

$$
\begin{aligned}
& x_{i}=\text { Weight of an investment } i \\
& R_{i}=\text { Return of investment } i \\
& E\left(R_{u}\right)=\text { Expected returns } \\
& \sigma_{i}^{2}=\text { Variance of investment } i \\
& \sigma_{i j}=\text { Covariance of investments } i \text { and } j
\end{aligned}
$$

and $u, m \& q$ are arbitrary symbols differentiating $i \&$ $u$ expected returns and non-diversifiable \& diversifiable variances respectively.

To find the weight of investment $i$ that will maximize expected returns and minimize total risk we apply the classical optimization method with no constraints See Rao (1994). We thus differentiate the expression;

$E\left(R_{u}\right)-\sigma_{m}{ }^{2}=E\left(\sum_{i=1}^{\infty} x_{i} R_{i}\right)-\sum_{i=1}^{\infty} x_{i}{ }^{2} \sigma_{i}{ }^{2}-2 \sum_{i=1}^{\infty} \sum_{j=1}^{\infty} x_{i} x_{j} \sigma_{i j}, i \neq j$

with respect to $X_{i}$ i.e.

$$
\frac{\partial\left\{E\left(R_{u}\right)-P_{m}^{2}\right\}}{\partial x_{i}}=E\left(R_{i}\right)-2 x_{i} \sigma_{i}^{2}-2 \sum_{j=1}^{\infty} x_{j} \sigma_{i j}=0, i \neq j
$$

and differentiate

$P_{m}{ }^{2}+P_{q}{ }^{2}=\sum_{i=1}^{\infty} x_{i}{ }^{2} \sigma_{i}{ }^{2}+2 \sum_{i=1}^{\infty} \sum_{j=1}^{\infty} x_{i} x_{j} \sigma_{i j}+\sum_{i=1}^{\infty} x_{i}{ }^{2} \sigma_{i}{ }^{2}, i \neq j$

with respect to $X_{i}$, i.e.

$$
\frac{\partial\left\{P_{m}^{2}+P_{q}^{2}\right\}}{\partial x_{i}}=4 x_{i} \sigma_{i}^{2}+2 \sum_{j=1}^{\infty} x_{j} \sigma_{i j}=0, i \neq j
$$

where $E\left(R_{u}\right)-P_{m}^{2}=$ maximum returns (derived by subtracting diversifiable variance from expected returns)

$P_{m}{ }^{2}+P_{q}^{2}=$ total variance (derived by adding diversifiable variance to non-diversifiable variance)
Note:

i) The second derivative of (4) is equal to $-2 \sigma_{i}^{2}$ implying that $x_{i}$ obtained will always maximize returns.

ii) The second derivative of (5) is equal to $4 \sigma_{i}^{2}$ implying that $x_{i}$ obtained will always minimize risk. See Rao (1994).

Equate (4) to (5) to get, the expected returns of investment $i$.

$$
\begin{gathered}
E\left(R_{i}\right)-2 x_{i} \sigma_{i}^{2}-2 \sum_{j=1}^{\infty} x_{j} \sigma_{i j}=4 x_{i} \sigma_{i}^{2}+2 \sum_{j=1}^{\infty} x_{j} \sigma_{i j}, i \neq j \\
E\left(R_{i}\right)=6 x_{i} \sigma_{i}^{2}+4 \sum_{j=1}^{\infty} x_{j} \sigma_{i j}, i \neq j \\
\frac{1}{2} E\left(R_{i}\right)=3 x_{i} \sigma_{i}^{2}+2 \sum_{j=1}^{\infty} x_{j} \sigma_{i j}, i \neq j
\end{gathered}
$$

Hence for infinite investments, values of $x_{i}$ are given by the expression

$$
\left(\begin{array}{llll}
3 \sigma_{1}^{2} & 2 \sigma_{12} & \ldots & 2 \sigma_{1 \infty} \\
2 \sigma_{21} & 3 \sigma_{2}^{2} & \ldots & 2 \sigma_{2 \infty} \\
\vdots & \ddots & \vdots \\
2 \sigma_{\infty 1} & \ldots & 3 \sigma_{\infty}^{2}
\end{array}\right)\left(\begin{array}{l}
x_{1} \\
x_{2} \\
\vdots \\
x_{\infty}
\end{array}\right)=\frac{1}{2}\left(\begin{array}{c}
E\left(R_{1}\right) \\
E\left(R_{2}\right) \\
\vdots \\
E\left(R_{\infty}\right)
\end{array}\right)
$$

Therefore, it follows from the derived values of $X_{i}$ in equation (7) and substituting them in the square root of equations (2) \& (3) that the true function for portfolio diversifiable risk is given by

$$
\left(\sum_{i=1}^{\infty} x_{i}^{2} \sigma_{i}^{2}+\sum_{i=1}^{\infty} \sum_{j=1}^{\infty} x_{i} x_{j} \sigma_{i j}\right)^{\frac{1}{2}}, i \neq j
$$

and that for portfolio non-diversifiable risk is

$$
\sum_{i=1}^{\infty}\left(x_{i}^{2} \sigma_{i}^{2}\right)^{\frac{1}{2}}
$$

\subsection{Empirical Study Using Sampled Data}

In this section, an empirical study is done to check if the true functions developed in the previous section work as estimators.

i) The data used was turnover of shares for Kenya Commercial Bank (KCB) given in Appendix 5 and East African Breweries Limited given in Appendix 6

First we normalize /standardize the data by taking logarithms and getting the first difference i.e. $\log$ 
$\left(\frac{y_{t}-y_{t-1}}{y_{t-1}-y_{t-2}}\right)$, whereby the sum of the ratios of the values of the difference between consecutive periods and the earlier of these periods will give the trend line,
To find the value of $x_{1}$ that minimizes portfolio risk we differentiate $P_{p}^{2}$ with respect to $x_{1}$ and equate it to zero

KCB turnover of shares

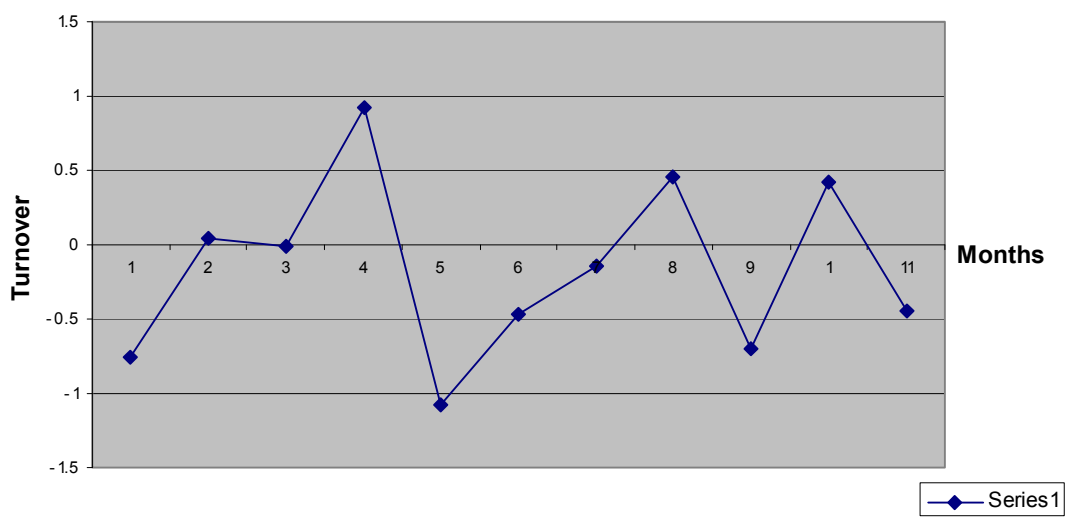

Figure 1: A plot of normalized turnover per month.

see Figure 1 given byMurray in 1961 .

Final values for finding the risks are given by the weights,

$$
\left(\begin{array}{l}
x_{1} \\
x_{2}
\end{array}\right)=0.552\left(\begin{array}{l}
3(0.3621844) 2(-0.167223) \\
2(-0.167223) 3(0.590005)
\end{array}\right)\left(\begin{array}{l}
\frac{1}{2}(-0.158996) \\
\frac{1}{2}(-0.142371)
\end{array}\right)
$$

where,

$$
\begin{aligned}
& \text { variance of } \mathrm{KCB}=0.3621844 \\
& \text { variance of } \mathrm{EABL}=0.590005 \\
& \text { covariance of } \mathrm{KCB} \& \mathrm{EABL}=0.167223 \\
& \text { expected returns of } \mathrm{KCB}=-0.158996 \\
& \text { expected returns of } \mathrm{EABL}=-0.142371
\end{aligned}
$$

Therefore Diversifiable risk of a portfolio of $\mathrm{KCB}$ $\&$ EABL $=0.082687821$ or $8.268 \%$ and its non diversifiable risk $=8.88 \%$.

ii) If we assume that $x_{i} \geq 0$ implying that sales are always positive and $\sum_{i=1}^{\infty} x_{i}=1$ implying perfect market conditions for the same data as in i) above (Markowitz assumptions) then

$$
P_{p}^{2}=x_{1}^{2} \sigma_{1}^{2}+x_{2}^{2} \sigma_{2}^{2}+2 x_{1} x_{2} \sigma_{12}
$$

where $P_{p}^{2}=$ portfolio variance.

$$
\begin{gathered}
\frac{\partial P_{p}^{2}}{\partial x_{1}}=2 x_{1} \sigma_{1}^{2}+2 x_{2} \sigma_{12} \\
2 x_{1} \sigma_{1}^{2}-2\left(1-x_{1}\right) \sigma_{12}=0 \\
2 x_{1} \sigma_{1}^{2}+2 \sigma_{12}-2 x_{1} \sigma_{12}=0 \\
0.724369 x_{1}+0.33444-0.33444 x_{1}=0 \\
0.389929 x_{1}=-0.33444 \\
x_{1}=\frac{-0.33444}{0.389929}
\end{gathered}
$$

Note: The negative numerator value $x_{1}$ indicates short selling. (Act of selling securities you do not own) since $x_{i} \geq 0, \quad x_{1}$ becomes

$$
x_{1}=\frac{0.33444}{0.389929}=0.85769
$$




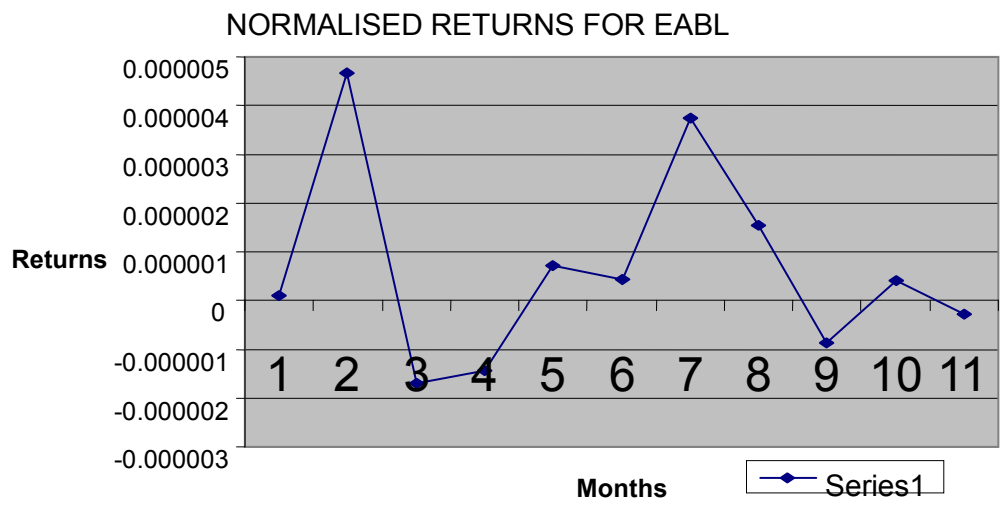

Figure 2: Normalized / Standardized Returns of EABL (derived by taking the first differences of the returns of shares, then the reciprocal of these differences).

since $\sum_{i=1}^{\infty} x_{i}=1 \quad, \quad x_{2}=1-x_{1}=0.1423053$ and

Diversifiable risk $=85.769 \%$ while Non-diversifiable risk $=14.23 \%$

iii) When we use returns of shares of $\mathrm{KCB}$ from Appendix 1 and EABL (Figure 2) from Appendix 4 we are not making any of the above assumptions

The final results are as follows, the weights

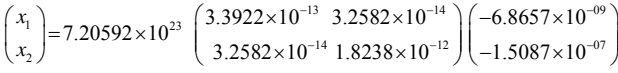

where

$3($ variance of $\mathrm{KCB})=3.3922 \times 10^{-13}$

$3($ variance of EABL $)=1.8238 \times 10^{-12}$

$2($ covariance of $\mathrm{KCB} \& \mathrm{EABL})=3.2582 \times 10^{-14}$

$1 / 2($ value for expected returns of $\mathrm{KCB})=-6.8657$

$\times 10^{-09}$

$1 / 2($ value for expected returns of EABL $)=-1.5087$

$\times 10^{-07}$

$x_{1}=-5220, x_{2}=-198436.9026$

Therefore diversifiable risk $=5.310$ and nondiversifiable risk $=17.215 \%$

THEOREM 1: Non-diversifiable risk, $\left(x_{i}^{2} \sigma_{i}^{2}\right)^{\frac{1}{2}}$ of a given investment $i$ remains unchanged for $i=1,2,3$, $\ldots, \infty$, investment of a given portfolio.
We make the following assumptions;

i) $-\infty<x_{i}<\infty$

ii) For diversifiability, $0 \leq x_{i}^{2} \sigma_{i}^{2}<\infty$ and for non diversifiability, $x_{i}^{2} \sigma_{i}^{2}=z$, where $0 \leq z<\infty$.

iii) Sampled data is normally distributed and representative of the population.

iv) Variances of investments $i=1,2,3, \ldots, \infty$. are uncorrelated for non-diversifiability.

\section{Proof:}

From equation (5), the value of $x_{1}$ that minimizes risk for a two sampled investment portfolios is given by,

$$
\begin{array}{r}
\frac{\partial\left(P_{m}^{2}+P_{n}^{2}\right)}{\partial x_{1}}=4 x_{1} s_{1}^{2}+2 x_{2} s_{12} \\
4 x_{1} s_{1}^{2}+2 x_{2} s_{12}=0 \\
4 x_{1} s_{1}^{2}=-2 x_{2} s_{12} \\
\frac{4 x_{1} s_{1}^{2}}{4 s_{1}^{2}}=\frac{-2 x_{2} s_{12}}{4 s_{1}^{2}} \\
x_{1}=-\frac{1}{2} \frac{x_{2} s_{12}}{s_{1}^{2}}
\end{array}
$$

For three investments the value of $x_{1}$ that minimizes risk is given by,

$$
\frac{\partial\left(P_{m}^{2}+P_{n}^{2}\right)}{\partial x_{1}}=4 x_{1} s_{1}^{2}+2 x_{2} s_{21}+2 x_{3} s_{31}=0
$$


which gives

$$
4 x_{1} s_{1}^{2}=-2 x_{2} s_{21}-2 x_{3} s_{31}
$$

so that

$$
x_{1}=-\frac{1}{2} \frac{x_{2} s_{21}}{s_{1}^{2}}-\frac{1}{2} \frac{x_{3} s_{31}}{s_{1}^{2}}
$$

For four investments the value of $x_{1}$ that minimizes risk is given by,

$$
x_{1}=-\frac{1}{2} \frac{x_{2} S_{21}}{s_{1}{ }^{2}}-\frac{1}{2} \frac{X_{3} S_{31}}{s_{1}{ }^{2}}-\frac{1}{2} \frac{x_{4} S_{41}}{s_{1}{ }^{2}}
$$

continuing in the same manner we see that for infinite investments the value of $X_{1}$ that minimizes risk is given by,

$$
x_{1}=-\frac{1}{2} \frac{X_{2} S_{21}}{s_{1}{ }^{2}}-\frac{1}{2} \frac{X_{3} S_{31}}{s_{1}{ }^{2}}-\frac{1}{2} \frac{X_{4} S_{41}}{S_{1}{ }^{2}} \ldots \frac{1}{2} \frac{X_{\infty} S_{\infty 1}}{S_{1}{ }^{2}}
$$

Similarly $x_{2}, x_{3}, \ldots, x_{\infty}$ can be obtained.

Taking expectations of equations (10), (11), (12), (13), to remove bias in the sample variance and considering the assumption (iv) we obtain

$$
\begin{aligned}
& E\left(x_{1} s_{1}^{2}\right)=E\left(-\frac{1}{2} x_{2} s_{21}\right) \\
& x_{1} E\left(s_{1}^{2}\right)=-\frac{1}{2} x_{2} E\left(s_{21}\right) \\
& x_{1}\left(\frac{n-1}{n}\right) \sigma_{1}^{2}=\frac{1}{2} x_{2}(0) \\
& \text { as } n \rightarrow \infty \\
& x_{1} \sigma_{1}^{2}=0
\end{aligned}
$$

where $\mathrm{n}$ is the sample size and $\mathrm{n}>1$. NOTE: $E\left(\sigma_{i j}\right)=$ 0 from assumption (v) . For equation (11),

$$
\begin{aligned}
& E\left(x_{1} s_{1}^{2}\right)=E\left(-\frac{1}{2} x_{2} s_{21}\right)+E\left(-\frac{1}{2} x_{3} s_{31}\right), \\
& x_{1}\left(\frac{n-1}{n}\right) \sigma_{1}^{2}=-\frac{1}{2} x_{2}(0)-\frac{1}{2} x_{3}(0),
\end{aligned}
$$

as $n \rightarrow \infty$

$$
x_{1} \sigma_{1}^{2}=0 \text {. }
$$

Similarly for investments $4,5,6, \ldots, \infty, x_{i} \sigma_{i}^{2}=0$.Thus non-diversifiable risk estimator (since we are using sampled data) is $P_{q}=\left(x_{i}^{2} \sigma_{i}^{2}\right)^{\frac{1}{2}}$ of investment $i=1,2$, $\ldots, \infty$, for a given portfolio remains unchanged.

iv) Analysis of returns of shares of three investments (see Appendix 1,2 and 3) gives the following results,

$$
\begin{aligned}
\left(\begin{array}{l}
x_{1} \\
x_{2} \\
x_{3}
\end{array}\right) & =15097 \times 10^{21}\left(\begin{array}{rrr}
-1.14589 \times 10^{-18} & 2.82915 \times 10^{-20} & -9.10521 \times 10^{-15} \\
2.82915 \times 10^{-20} & -9.10521 \times 10^{-15} & 6.83994 \times 10^{-21} \\
-9.10521 \times 10^{-15} & 6.83994 \times 10^{-21} & -4.85532 \times 10^{-20}
\end{array}\right) \\
& \left(\begin{array}{c}
-6.86872 \times 10^{-08} \\
-1.50874 \times 10^{-07} \\
3.32536 \times 10^{-07}
\end{array}\right)
\end{aligned}
$$

where the right hand side is the product of the reciprocal of determinant of variance covariance matrix, inverse of variance covariance matrix and values representing means of the three investment returns.

$$
\begin{aligned}
& x_{1}=-3.484843067 \\
& x_{2}=1.581127467 \\
& x_{3}=0.719814553
\end{aligned}
$$

Thus diversifiable risk of a portfolio of $\mathrm{KCB}, \mathrm{EABL}$ \&STAN CHART $=2.54382 \times 10^{-06} \%$, and its nondiversifiable risk $=8.93518 \times 10^{-06} \%$.

For a two investment portfolio of KCB and EABL diversifiable risk for $\mathrm{KCB}$ is 0.01755 and that of EABL is 0.15460 . For an investment portfolio of $\mathrm{KCB}$, EABL and STANCHART diversifiable risk for KCB is $2.15374 \times 10^{-09}$, EABL is $8.71066 \times 10^{-08}$ and that of STAN CHART is $9.14787 \times 10^{-11}$.

Clearly portfolio risk has been diversified but nondiversifiable risk for $\mathrm{KCB}$ and $\mathrm{EABL}$ is not the same as that one for two investments as per the definition of non-diversifiable risk and the findings of theorem one. This is also true for turnover of a three and four investment portfolio. Thus there is some white noise in the data analyzed. We therefore remedy our estimator for non-diversifiable risk to include the random error.

This is done by adding $\sum_{i=1}^{\infty}\left(s_{e_{i}}^{2}\right)^{\frac{1}{2}}$ to the nondiversifiable risk estimator. We thus denote this model estimator as, 


$$
p_{G}=\sum_{i=1}^{\infty}\left(x_{i}^{2} s_{i}^{2}\right)^{\frac{1}{2}}+\sum_{i=1}^{\infty}\left(s_{e_{i}}^{2}\right)^{\frac{1}{2}}
$$

where $e_{i}$ is an independent random variable with mean zero and variance $\frac{s_{e i}{ }^{2}}{n-1}$ (i.e. sample variance)

THEOREM 2: The non-diversifiable risk model estimator $P_{G}$ is a consistent estimator of non-

diversifiable risk $P_{q}$.

We make the following assumptions;

i) $e_{i}$ is an independent random variable with mean zero

$$
\text { i.e. } E\left(\sigma_{e_{i}}{ }^{2}\right)=0 \text { and variance } \frac{\sigma_{e_{i}}{ }^{2}}{n-1}
$$

ii) Variances of investments $i=1,2,3, \ldots, \infty$. are uncorrelated.

iii) Sampled data is representative of the population and is normally distributed.

Where G \& q are arbitrary symbols.

\section{Proof:}

By definition we note that

$$
P_{G}=\sum_{i=1}^{\infty}\left(x_{i}^{2} s_{i}^{2}\right)^{\frac{1}{2}}+\sum_{i=1}^{\infty}\left(s_{e_{i}}^{2}\right)^{\frac{1}{2}}
$$

Thus

$$
s_{G}{ }^{2}=\sum_{i=1}^{\infty} x_{i}{ }^{2} s_{i}{ }^{2}+2 \sum_{i=1}^{\infty}\left(x_{i}^{2} s_{i}^{2}\right)^{\frac{1}{2}} \sum_{i=1}^{\infty}\left(s_{e_{i}}{ }^{2}\right)^{\frac{1}{2}}+\sum_{i=1}^{\infty} s_{e_{i}}{ }^{2}
$$

The expectation of equation (15) is

$$
E\left(P_{G}^{2}\right)=E\left(\sum_{i=1}^{\infty} x_{i}^{2} s_{i}^{2}\right)+E\left[2 \sum_{i=1}^{\infty}\left(x_{i} s_{i}\right)\left(s_{e_{i}}\right)\right]+E\left(\sum_{i=1}^{\infty} s_{e_{i}}{ }^{2}\right)
$$

Hence

as $n \rightarrow \infty$

$$
E\left(P_{G}^{2}\right)=\frac{n-1}{n}\left(\sum_{i=1}^{\infty} x_{i}^{2} \sigma_{i}^{2}\right)
$$

Published by Atlantis Press

Copyright: the authors

$$
E\left(P_{G}^{2}\right)=(n-0)\left(\sum_{i=1}^{\infty} x_{i}^{2} \sigma_{i}^{2}\right)
$$

Note : Since $s_{i}{ }^{2}$ is the sample variance of sampled data of investment $i$ which is normally distributed thus there is bias in the unmodified form of the sample variance.

Therefore

$$
\left(P_{G}\right)=\sum_{i=1}^{\infty}\left(x_{i}^{2} \sigma_{i}^{2}\right)^{\frac{1}{2}}=\sigma_{q}
$$

This proves that $P_{G}$ is an unbiased estimator of $P_{q}$.

From (15), observe that

$$
\begin{aligned}
& \operatorname{var}\left(P_{G}^{2}\right)=\operatorname{var}\left(\sum_{i=1}^{\infty} x_{i}^{2} s_{i}^{2}\right)+\operatorname{var}\left[\sum_{i=1}^{\infty}\left(x_{i}^{2} s_{i}^{2}\right)^{\frac{1}{2}}\left(s_{e_{i}}^{2}\right)^{\frac{1}{2}}\right]+\operatorname{var}\left(\sum_{i=1}^{\infty} s_{e_{i}}{ }^{2}\right) \\
& =\left(\frac{2}{n-1} \sum_{i=1}^{\infty} x_{i}^{4} \sigma_{i}^{4}\right)+\left(\frac{2}{n-1}\right)\left(\frac{2}{n-1}\right)\left(\sum_{i=1}^{\infty} x_{i}^{4} \sigma_{i}^{4}\right)\left(\sum_{i=1}^{\infty} \sigma_{e_{i}}^{4}\right) \\
& \operatorname{var}\left[\left(\sum_{i=1}^{\infty} x_{i}^{2} \sigma_{i}^{2}\right)^{\frac{-1}{2}}\left(\sum_{i=1}^{\infty} \sigma_{e_{i}}{ }^{-\frac{1}{2}}\right]+\left(\frac{2}{n-1}\right)\left(\sum_{i=1}^{\infty} \sigma_{e_{i}^{4}}^{4}\right.\right. \\
& =\frac{2}{n-1}\left[\left(\sum_{i=1}^{\infty} x_{i}^{4} \sigma_{i}^{4}\right)+\left(\frac{2}{n-1}\right)\left(\sum_{i=1}^{\infty} x_{i}^{4} \sigma_{i}^{4}\right)\left(\sum_{i=1}^{\infty} \sigma_{e_{i}}{ }^{4}\right) \operatorname{var}\left[\left(\sum_{i=1}^{\infty} x_{i}^{2} \sigma_{i}^{2}\right)^{-\frac{1}{2}}\left(\sum_{i=1}^{\infty} \sigma_{e_{i}}{ }^{2}\right)^{\frac{-1}{2}}\right]+\left(\sum_{i=1}^{\infty} \sigma_{e_{i}}{ }^{4}\right)\right]
\end{aligned}
$$

Note: In equation (16), $\left(x_{i}^{2} \sigma_{i}^{2}\right)^{\frac{1}{2}}$ is rewritten as $\left(x_{i}^{2} \sigma_{i}^{2}\right)\left(x_{i}^{2} \sigma_{i}^{2}\right)^{-\frac{1}{2}}$ and $\left(\sigma_{e_{i}}{ }^{2}\right)^{\frac{1}{2}}$ as $\left(\sigma_{e_{i}}{ }^{2}\right)\left({\sigma_{e_{i}}}^{2}\right)^{-\frac{1}{2}}$ to assist in simplification. Also $\operatorname{var}\left(s^{2}\right)=\frac{2}{n-1} \sigma^{4}$ as proved by Tobago (2010)

Recalling that as $n \rightarrow \infty E\left(\sigma_{G}\right)=\sigma_{q}$, it follows from this result (i.e. $\operatorname{var}\left(\sigma_{G}\right) \rightarrow 0$ ) that $P_{G}$ is a consistent estimator of Non-diversifiable risk.

\section{Discussion}

\subsection{Presentation of Results}

4.1.1 Forecasts of Time Series

In forecasting we used GARCH (Generalized AutoRegressive Conditional Heteroskedastic) models. This is because the time series values have low valued correlations. In GARCH modeling the true GARCH (A, B) model parameters of the time series are entered. These parameters correspond to a given $\operatorname{GARCH}(\mathrm{A}, \mathrm{B})$ model for the conditional variance $F(t)$ and innovations $\mathrm{Y}(\mathrm{t})$, sequences 


$$
\begin{aligned}
F(t)= & L(t)+S(1) * F(t-1)+S(2) * F(t-2)+\cdots+ \\
& S(P) * F(t-P)+W(1) Y^{2}(t-1)+W(2) Y^{2}(t-2)+ \\
& \cdots+W(Q) Y^{2}(t-Q)
\end{aligned}
$$

for time steps $t=1,2, \ldots N$, where

$S=$ order of AR

$W=$ order of MA

$A \& B=$ model order determined by the number of elements of $S \& W$

$S, W=$ coefficient.

$\mathrm{t}=$ the current time index.

$Y(t)=$ square $\operatorname{root} F(t) L(t)$ where $L(\underline{\mathrm{t}})$ is an identical and independent sequence $N(0,1)$ and $Y$ and $F$ are related.

The forecasts for the investment time series from Appendix 1 through to Appendix 3 are given in Table I and Table II.
4.1.2 Prediction of Expected Returns Diversifiable Risk and Non-Diversifiable Risk

Using the forecasts from Section 4.1.1 above and equations 7,8 and 9 the predictions for expected returns, diversifiable risk and non-diversifiable risk are made as Table III and Table IV.

\subsection{Result Discussion}

\subsubsection{Derivation of Forecasts}

In forecasting using GARCH models we let $\mathrm{t}$ be the current time index, $\{\mathrm{F}(\mathrm{t})\}$ be the return series of interest, $\{\mathrm{Y}(\mathrm{t})\}$ the innovations noise process and $\mathrm{L}(\mathrm{t})$ be an identical and independent sequence. The input coefficient vectors AR (Autoregressive) and MA (Moving Average) are specified exactly as they would

TABLE I: The table below represents forecasted returns of shares of the given companies in Kenyan shillings ( ksh).

\begin{tabular}{|l|l|l|l|l|}
\hline COMPANY & EABL & ICDC & KCB & STAN CHART \\
\hline 1 & 55660000 & 3881300 & 38460000 & 32670000 \\
\hline 2 & 42710000 & 3590200 & 29520000 & 25070000 \\
\hline 3 & 36010000 & 3320800 & 24880000 & 21130000 \\
\hline 4 & 31720000 & 3071700 & 21920000 & 18620000 \\
\hline 5 & 28680000 & 2841300 & 19810000 & 16840000 \\
\hline 6 & 26370000 & 2628200 & 18230000 & 15480000 \\
\hline 7 & 24550000 & 2431000 & 16960000 & 14400000 \\
\hline 8 & 23050000 & 2248600 & 15930000 & 13540000 \\
\hline 9 & 21810000 & 2080000 & 15070000 & 12790000 \\
\hline 10 & 20740000 & 1923900 & 14330000 & 12180000 \\
\hline 11 & 19820000 & 1779600 & 13690000 & 11630000 \\
\hline 12 & 19000000 & 1646100 & 13130000 & 11160000 \\
\hline 13 & 18290000 & 1522600 & 12640000 & 10730000 \\
\hline 14 & 17650000 & 1408400 & 12200000 & 10360000 \\
\hline 15 & 17070000 & 1302800 & 11790000 & 10020000 \\
\hline 16 & 16540000 & 1205000 & 11430000 & 9710000 \\
\hline 17 & 16060000 & 1146000 & 11100000 & 9420000 \\
\hline
\end{tabular}

TABLE II: The table below represents forecasts of turnover of shares of the given companies in ksh.

\begin{tabular}{|l|l|l|l|l|}
\hline COMPANY & EABL & ICDC & KCB & $\begin{array}{l}\text { STAN/ } \\
\text { CHART }\end{array}$ \\
\hline 1 & 105230000 & 8609700 & 406500000 & 69829000 \\
\hline 2 & 99830000 & 7718800 & 385640000 & 66245000 \\
\hline 3 & 94710000 & 6920100 & 365850000 & 62846000 \\
\hline 4 & 89850000 & 6204100 & 347080000 & 59621000 \\
\hline 5 & 85240000 & 5562100 & 329270000 & 56561000 \\
\hline 6 & 80860000 & 4986600 & 312370000 & 53659000 \\
\hline
\end{tabular}


be read from the ARMA (Autoregressive Moving Average) (R,M) model equation when solved for $F(t)$ : $F$ $(\mathrm{t})=\mathrm{L}(\mathrm{t})+\mathrm{AR}(1) \mathrm{F}(\mathrm{t}-1)+\ldots+\mathrm{AR}(\mathrm{R}) \mathrm{F}(\mathrm{t}-\mathrm{R})+\mathrm{Y}(\mathrm{t})$ MA (1) Y (t-1) +... MA (M) Y (t-m) series. To estimate, and make forecasts from the $\operatorname{GARCH}(\mathrm{A}, \mathrm{B})$ parameters from the equation: $\mathrm{Y}(\mathrm{t})=$ square root $(\mathrm{F}(\mathrm{t}) * \mathrm{~L}(\mathrm{t}))$ where $\mathrm{Y}(\mathrm{t})$ represents innovations noise process, you simulate (i.e., to

TABLE III: Seventeen month predictions of returns of shares of the given companies

\begin{tabular}{|c|c|c|c|}
\hline Portfolio & $\begin{array}{c}\text { Expected } \\
\text { returns }\end{array}$ & $\begin{array}{c}\text { Diversifiable } \\
\text { risk }\end{array}$ & $\begin{array}{c}\text { Non-diversifiable } \\
\text { risk }\end{array}$ \\
\hline EABL \& ICDC & 0.559 or $55.9 \%$ & 0.219 or $22 \%$ & 0.223 or $22.32 \%$ \\
\hline $\begin{array}{c}\text { ICDC \& } \\
\text { STANCHART }\end{array}$ & 1.27 or $127 \%$ & 0.503 or $50.3 \%$ & 0.5104 or $51.04 \%$ \\
\hline $\begin{array}{c}\text { EABL \& } \\
\text { STANCHART }\end{array}$ & 1.14 or $114 \%$ & 0.478 or $47.8 \%$ & 0.478 or $47.84 \%$ \\
\hline $\begin{array}{c}\text { EABL, ICDC } \\
\text { \& STANCHART }\end{array}$ & 1.34 or $134 \%$ & 0.532 or $53.2 \%$ & 0.552 or $55.21 \%$ \\
\hline
\end{tabular}

TABLE IV: Six month Predictions of turnover of shares of the given companies

\begin{tabular}{|c|c|c|c|}
\hline Portfolio & $\begin{array}{c}\text { Expected } \\
\text { returns }\end{array}$ & $\begin{array}{c}\text { Diversifiable } \\
\text { risk }\end{array}$ & $\begin{array}{c}\text { Non-diversifiable } \\
\text { risk }\end{array}$ \\
\hline EABL \& ICDC & $1822 \%$ & $150.82 \%$ & $255 \%$ \\
\hline ICDC \& STANCHART & $1821 \%$ & $150.81 \%$ & $262 \%$ \\
\hline EABL \& STANCHART & $2063 \%$ & $203 \%$ & $203.2 \%$ \\
\hline $\begin{array}{c}\text { EABL, ICDC } \\
\text { \& STANCHART }\end{array}$ & $474 \%$ & $83.79 \%$ & $95.3 \%$ \\
\hline
\end{tabular}

Note that the coefficients of $\mathrm{F}(\mathrm{t})$ and $\mathrm{Y}(\mathrm{t})$ are assumed to be 1, and are not part of the AR / MA input vectors.

For the following ARMA $(2,2)$ model, of ICDC

$\mathrm{F}(\mathrm{t})=0.036 \mathrm{Y}(\mathrm{t}-1)-0.002 \mathrm{Y}(\mathrm{t}-2)+\mathrm{Y}(\mathrm{t})+0.402 \mathrm{Y}(\mathrm{t}-$ 1) $+-0.107 \mathrm{Y}(\mathrm{t}-2)$

$\mathrm{AR}=[0.036-0.002]$ and $\mathrm{MA}=[0.402-0.107]$. The first 20 weights of the infinite order AR approximation may be found as follows:

$\mathrm{ZI}=\operatorname{garchar}([0.036-0.002],[0.402-0.107], 20)$;

where ZI represents weights of the polynomials generated and garchar converts $\mathrm{j}$-th lag of the return series and innovations processes $F(t-j)$ and $Y(t-j)$, respectively. To maintain consistency, the $\mathrm{j}$-th element of the truncated infinite-order auto- regressive output vector, ZI (j), is the coefficient of the $\mathrm{j}$-th lag of the observed return series, $\mathrm{F}(\mathrm{t}-\mathrm{j})$, in the infinite order representation of the input ARMA $(\mathrm{R}, \mathrm{M})$ process. The $\mathrm{AR}$ and MA input vectors differ from the corresponding AR and MA 'polynomials' formally presented in time reverse-engineer the process for comparison) (see Bollersler (1986), Box, Jenkins (1994), Engle and Robert (1982), Hamilton 1994). Figures 3 and 4 show that the forecasted time series is normally distributed thus there is no need for its standardization before making predictions. This also explains the downward trend of the forecasts i.e. to maintain the bell like shape of the curve indicative of normally distributed data. (Note that the plots show values for half the distribution because both halves are identical). See Lucey (2000). Returns of shares are forecasted in the long term since these data were prepared for long term investors who are not ready to sell their shares in the near future. Short term forecasts are meant for speculative buyers who are risk averse and can sell their shares anytime the prices go up. The estimators used to predict future expected returns, diversifiable risk and nondiversifiable risk are applicable within the normal ranges of negative infinity to positive infinity. This is reflected in Tables III and IV where values range from the tens to hundreds to thousands etc, compared to Markowitz estimator of diversifiable risk whose weight values $X_{i}$ must be greater than or equal to zero i.e. $x_{i} \geq 0$. The sum of these weights for any number of investments in a portfolio must be equal to one i.e. 
$\sum_{i=1}^{\infty} x_{i}=1$. The first assumption limits the data set being used since if it is one with negative returns the estimator collapses. This means that one assumes positive returns always and yet many a time financial institutions experience losses or negative sales. The second assumption implies perfect market conditions, i.e. the portfolio is efficient with no systematic risk present. Under normal financial environments this is not true since fluctuations in returns do occur frequently. The development of an estimator for nondiversifiable risk in this study is an indication of the presence

of market risk.

For $R_{k}$ the return of $k$ CAPM is given by

$$
E\left(R_{k}\right)=E\left(R_{f}\right)+\frac{\left(E\left(R_{m}\right)-E\left(R_{f}\right)\right) \sigma_{k m}}{\sigma_{m}^{2}}
$$

where

$m=$ market portfolio

$E\left(R_{k}\right)=$ expected returns of the risky security $k$

$E\left(R_{f}\right)=$ risk free rate of return

$E\left(R_{m}\right)=$ expected returns of the market portfolio $m$

$\sigma_{m}{ }^{2}=$ variance of the market portfolio $m$

$\sigma_{k m}=$ covariance between the single risky security

$k$ and the market portfolio $m$

This model works under the following assumptions, See Andrew (1993):

i) All investors are risk-averse and measure risk in terms of standard deviation of portfolio return (as for the Markowitz model).

ii) All investors have a common time horizon for investment decision making ( e.g. one month or two years ).

iii) All investors have identical subjective estimates of future returns and risks for all securities.

There exists a risk-free asset and all investors may borrow or lend unlimited amounts at the risk-free nominal rate of interest.

iv) All securities are completely divisible, there are no transaction costs or differential taxes, and there are no restrictions on short-selling.
Information is freely and simultaneously available to all investors.

Although there is a great deal of evidence which supports CAPM, much courage is required to develop a model on the basis of these assumptions. Many of them are clearly unrealistic, for example the assumption that there exists a risk-free asset and all investors may borrow or lend unlimited amounts at the risk-free nominal rate of interest. The model should therefore not be relied upon for more than general indications of the market pricing mechanism as seen in section 2.1. The estimators developed in this study have addressed the above short comings such that none of the above assumptions are made in deriving these estimators.

Furthermore the Beta factor i.e. $B_{k}=\frac{\sigma_{k m}}{\sigma_{m}{ }^{2}}$ is an indicator of non-diversifiable risk. This is not a good indicator since from the definition of non-diversifiable risk, there should not be any correlation between the various investments, yet the expression $\sigma_{k m}$ in the beta factor formulae represents covariance between single risky security $k$ and the market portfolio $\mathrm{M}$ which counterfeits the definition of non-diversifiable risk, thus giving weight to the doubts cast on the CAPM practical applicability by researchers in the 1980's. The predictions in tables III and IV indicate that the higher the risks the higher the expected returns. This is expected since high risks imply venturing into unknown areas. Thus one can only be motivated to do so if he/she expects big rewards for taking these risks. This is experienced in financial markets where monopolists venture into new business areas. If their ventures are successful they expect to reap maximum benefit since there is no competition from other financial institutions. If they fail in their ventures they stand to incur heavy losses since they will not be able to recover their base capital among other costs incurred.

There would be no other financial institution trading in the same items thus they cannot sell their business to them or merge with these financial institutions in order to diversify their risk thus minimizing it and reaping the benefits of economies of scale.

The predictions show a clear distinction between diversifiable risk and non-diversifiable risk, whereby non-diversifiable risk is always the higher of the two risks. Table IV which has six month predictions of turnover of shares shows this observation clearly. Unlike the data for returns of shares, the data for 
turnover of shares is not derived using a common reference price. Variances in the time series tend to be huge leading to higher risks. The length of time the forecasts postulate, i.e. six month have an impact on risk. Whereby investors can sell their investments easily when the prices are high thus returns will be high. The high returns will thus be accompanied by high risks as experienced by monopolists.

\section{Conclusion and Recommendations}

\subsection{Conclusion}

In this study a non-diversifiable risk model estimator, diversifiable risk and expected return estimators have been developed. In doing so we have done away with the many theoretical like assumptions that are usually employed in similar studies as seen in Section 4.3.1 The presence of white noise in non-diversifiable risk has been established which confirms the fact that such a risk is independent i.e. cannot be diversified.

This paper confirms that the risks are high as it should be in the stock market due to the high volatility experienced. Moreover, our study indicates that diversification reduces diversifiable risk but not nondiversifiable risk. Investment analysts have relied on Markowitz estimator of risk Markowitz (1952), the market model and the CAPM to analyze the effect of risk in investment decision making. These have had various shortcomings as evidenced by earlier researchers (Section 2.0) and this study's findings (Section 4.3). Development of risk estimators and expected return estimators that have addressed these shortcomings in this study is expected to improve the accuracy of predicting future expected performance of financial institutions. Investment analysts can now rely on the predictions to make good investment decisions. Financial institutions can now venture into the unknown future financial environment knowing what to expect. Predictability of the future of financial institutions is expected to spill over to investment markets. Overtime investment markets have been known to be unstable, particularly stock, credit, bond and foreign exchange markets. It is hoped that a systematic method will be established which will ensure frequent determination and publication of non-diversifiable risk for respective financial institutions, i.e., those on NSE and other capital markets with a view to reducing their future uncertainties. Stabilized investment markets mean increased investor confidence. We should therefore expect to see an influx of investors in the investment markets.

A thriving investment market bolsters the economy. Such that we have increased levels of foreign exchange which strengthens the value of the Kenyan shilling. Imports and exports then become cheap thus influencing the economy positively. New financial institutions will be started and the existing ones sustained. Employment opportunities will be created leading to increased purchasing power, money supply and Gross Domestic Product. All these improve the economy and eventually the way of life of individuals in this economy. Lending and borrowing of funds is hoped to increase due to stable interest rates. Small scale businesses will thrive, improving the standards of living of individuals in these business environments.

Determination of non-diversifiable risk and prediction of future performance of financial institutions does not eliminate risk. Nevertheless their proper estimation enables financial analysts make accurate current and future business plans (Paul 2003). Expected future cash flows are made accurately by incorporating this determined risk in their discounting methods. Correct capital investment decision making is facilitated. Required levels of cash and cash equivalents will always be maintained leading to high profitability of the financial institutions. Capital allocation will also be made accurately, since the optimum portfolio will be accurately identified. Despite the good investment decision making and proper financial planning anticipated portfolio risk has to be addressed as an entity. If left unchecked it can cause unexpected losses. This is particularly for financial institutions which trade in interest related portfolios and foreign exchange trading portfolios. With the determination of total risk, risk management techniques are expected to be properly initiated and established, Jennifer (2003). Hedging schemes such as derivatives, options and futures are hoped to cost less, karithi (2003). Savings are anticipated in risk management departments which should be used to increase the wealth of owners of the financial institutions. These will then motivate them to continually invest in them thus sustaining their growth and development. 
Having discussed the positive impact this study is expected to have on the general environment, unstable or risky environments should be a thing of the past, while stabilized environments should be the norm.

\subsection{Recommendations}

From the above conclusive results this paper recommends the use of all derived estimators in both capital allocation in investment portfolios and net present value investment decision making criterion.

Risk is not only experienced in financial environments. It is also encountered in such areas as medical practices, whereby there is some risk attached to various curative methods. Notably are the radiotherapy and chemotherapy methods of curing cancer. The environment also experiences some health hazards due to environmental pollution or poor sanitation, i.e. environmental risk. It would be challenging to adapt the risk determining methods developed in this study in determining medical and environmental risks with a view to reducing them.

\section{References}

Andrew, A., Della, B., Philip, B., and Peter, E. (1995) Investment Mathematics and Statistics, pg. 208-257. Kluwer Law International

Box, G., Jenkins, G., Reinsel, G. (1994) "Time Series Analysis; Forecasting and control" Prentice Hall

Bollersler, T. (1986) "Generalized Autoregressive Conditional Heteroskedasticity" Journal of econometrics, vol. 31, pp 307-327

Dimson, E. (1988) Stock Market Anomalies, Cambridge University Press

Engle, R. (1982) "Autoregressive Conditional Heteroskedasticity with Estimates of the variance of United Kingdom Inflation “ Econometrica, vol. 50, pp.987-1007.

Hamilton, J. (1994) 'Time Series Analysis' Princeton University Press.

Harper, R. (2003) Asset Allocation, Decoupling and the opportunity cost of cash, Journal of portfolio management, Vol. 29 Issue 4, p25.

Jennifer, J. (2003) Risk Management at the World Bank Global Liquidity Portfolios, pp 11 - 17.

Karithi, M. (2003) Management of Foreign Exchange Risk, KASNEB Newsline pg 19-25

Lintner, J. (1965) The valuation of risk assets and the selection of risky investments in stock portfolios and capital budgets, Review of Economics and statistics, 47, pg 13-37.

Markowitz, H. (1952) Portfolio Selection, Efficient Diversification of Investments, Basil Blackwell.

Mossin, J. (1966) Equilibrium in a capital asset market, Econometrica, 34, pg 768-783, October

Murray, R.(1961) Theory and Problems of Statistics SI units, pg. 231, McGraw-Hill Book Company Nicholas, F. and Laverne, S. (1989) Quantitative Forecasting Methods, pg. 117 \&118, Pws-Kent.

McClure, P. (2003) Management's Discussion and Analysis, Financial Statements and Investment Portfolios International Finance Corporation 2003 Annual Report Volume 2 pg 11-15.

Macharia, P. (2001). NSE, Bulletin pg, 2-4 NSE

Rao. S. S. (1994) Optimization theory and application Wiley Eastern Limited New Age International p.gs. 37-40.

Raymond, B. (2000) Financial Management 6th edition pg, 123-134

Sharpe, W. (1964) "Capital Asset Prices: A Model of Market Equilibrium under conditions of Risk", Journal of Finance, Vol. 19, pp. 425-442.

Stulz, R. (1999). What's wrong with Modern Capital Budgeting? Financial Practice \& Education, Vol. 9 Issue 2, pp7, DP Publications

Taboga, M. (2010) 'Lectures on probability and statistics', http://www.statlect.com.

Vlaar, P. (2000) Value at Risk Models for Dutch Bond Portfolios. Journal of Banking and Finance, 24: 1131-1154.

Wilkes, F., Samuels, J., Brayshew, R. (1996) Management of company Finance, pg 262-265. International Thomson Business Press. 


\section{APPENDICES}

\section{Appendix 1:}

Table V: Returns For KCB Shares from January 2009 - December 2013 Base Price April 2009 in Kenyan Shillings (Ksh)

\begin{tabular}{|l|l|l|l|l|l|}
\hline MONTH & 2009 & 2010 & 2011 & 2012 & 2013 \\
\hline JAN & -254977217 & -4909732 & -48293377 & -28599388 & -176773446 \\
\hline FEB & -11858496 & -18114517 & -35537228 & -86093014 & -27392971 \\
\hline MAR & -20843003 & -11145914 & -20663935 & -235975275 & -235975275 \\
\hline APR & -35789720 & -20446319 & -16526970 & -249196506 & -201979585 \\
\hline MAY & -12178766 & -72691432 & -44283975 & -12896377 & -72325367 \\
\hline JUN & -31529069 & -69476411 & -12607319 & -24309319 & -3479830 \\
\hline JUL & -8193042 & -15160040 & -94872136 & -28713343 & -80326198 \\
\hline AUG & -8925414 & -78123604 & -73423079 & -16496101 & -30548808 \\
\hline SEP & -27908155 & -35911665 & -7891213 & -48476514 & -44356839 \\
\hline OCT & -6450228 & -7641496 & -23904507 & -60275745 & -31303040 \\
\hline NOV & -19916397 & -19712658 & -10867080 & -140518771 & -39819260 \\
\hline DEC & -6620513 & -2055670 & -4412974 & -16975041 & -61658147 \\
\hline
\end{tabular}

\section{Appendix 2:}

Table VI: Returns For Standard Chartered Shares from January 2009 - December 2013 Base Price April 2009 in Ksh

\begin{tabular}{|l|l|l|l|l|l|}
\hline MONTH & 2009 & 2010 & 2011 & 2012 & 2013 \\
\hline JAN & -10356582 & 2465938 & 529514 & 1111462 & 7044060 \\
\hline FEB & 114576 & 6572177 & 3748395 & 1485758 & 7846250 \\
\hline MAR & 328887 & 938150 & 4481874 & 393326 & 21271177 \\
\hline APR & -260376 & 811697 & 6695297 & -82382 & 21024330 \\
\hline MAY & -951995 & 473787 & 910638 & 713692 & 40984696 \\
\hline JUN & 435601 & -239449 & 2715433 & 1376041 & 53320718 \\
\hline JUL & 2712442 & 698182 & 3454344 & 2466946 & 14738214 \\
\hline AUG & 2979260 & 170156 & 2664586 & 3125082 & 45759692 \\
\hline SEP & 3627526 & 11828563 & 788886 & 789498 & 30389636 \\
\hline OCT & 2478381 & 6078253 & 2120709 & 2634216 & 250200283 \\
\hline NOV & 4948147 & 1699087 & 618373 & 4069588 & 83728614 \\
\hline DEC & 1474898 & -832158 & 543333 & 6367901 & 15751289 \\
\hline
\end{tabular}

Stan chart is one of the three companies with the highest returns and least negative sales thus analyzed for investment purposes. 


\section{Appendix 3:}

Table VII: Returns for ICDC (Industrial Commercial Development Corporation) Shares From January 2009 - December 2013 Base Price April 2009 1n Ksh.

\begin{tabular}{|l|l|l|l|l|l|}
\hline MONTH & 2009 & 2010 & 2011 & 2012 & 2013 \\
\hline JAN & 11935779 & 834948 & 3910778 & -661320 & -4407558 \\
\hline FEB & 418644 & 1115537 & 2724842 & -379153 & -1360183 \\
\hline MAR & 1346134 & 748676 & 3267626 & -614656 & -137580 \\
\hline APR & 3239774 & 130815 & 486736 & $-2644600 *$ & 89436 \\
\hline MAY & 971928 & 936465 & 3403992 & -980303 & 1238786 \\
\hline JUN & 731335 & -356349 & 9535859 & -1628149 & 3385594 \\
\hline JUL & 850178 & 458268 & 185853 & -10295746 & -510603 \\
\hline AUG & 1439235 & 344772 & 961124 & -32399844 & 15592897 \\
\hline SEP & 4163159 & 4570032 & -652724 & -236345 & 5216308 \\
\hline OCT & 2460198 & 945932 & 73658 & -552725 & 6314293 \\
\hline NOV & 774004 & 2910810 & -666640 & -572520 & 3275379 \\
\hline DEC & 1459217 & 507676 & -96840 & -148838 & 13410155 \\
\hline
\end{tabular}

* This value is calculated from Table XV as $20.875-38.375=-17.5 \mathrm{X} 151120=-2644600$

\section{Appendix 4:}

Table VIII: Returns For East African Breweries Shares From January 2009 - December 2013 Base Price April 2009 in Ksh.

\begin{tabular}{|l|l|l|l|l|l|}
\hline \multicolumn{1}{|c|}{ YEAR } & 2009 & 2010 & 2011 & 2012 & 2013 \\
\cline { 2 - 2 } & -10106177 & -173378 & 4433440 & 980372 & 22434220 \\
\hline JAN & 2715705 & -1470663 & 17493087 & 1298971 & 49769005 \\
\hline FEB & -9821081 & -830676 & 5217513 & 1314180 & 50841507 \\
\hline MAR & -283444 & -914474 & $0 *$ & 856305 & 90741122 \\
\hline APR & 1748910 & -2648273 & 2786088 & 3520085 & 137930125 \\
\hline MAY & 948375 & -7199135 & 459345 & 2908110 & 199612113 \\
\hline JUN & 489416 & 1106750 & 676910 & 13447207 & 22265976 \\
\hline JUL & 16667673 & -3985070 & -756480 & 14598393 & 323570569 \\
\hline AUG & 4112532 & 1861435 & 322465 & 22556215 & 155506703 \\
\hline SEP & 386565 & 3300665 & 4528066 & 8768165 & 162636994 \\
\hline OCT & -321409 & -9450660 & 1236078 & 29758680 & 177642340 \\
\hline NOV & 503414 & 1054648 & 4122929 & 60118940 & 82052882 \\
\hline DEC & & & & & \\
\hline
\end{tabular}

* is a rare value which indicates that the share price of April 2011 is at par with that of April 2009. 


\section{Appendix 5:}

TABLE IX: Turnover for KCB from shares for the years 2009 - 2013 IN KSH

\begin{tabular}{|l|l|l|l|l|l|}
\hline MONTH & 2009 & 2010 & 2011 & 2012 & 2013 \\
\hline JAN & 327531709 & 4107488 & 22019778 & 8954014 & 77310126 \\
\hline FEB & 57563116 & 18114517 & 16772678 & 25391488 & 11980046 \\
\hline MAR & 64039370 & 6958143 & 10979475 & 63794401 & 31424618 \\
\hline APR & 6232688 & 14910085 & 32051257 & 67655160 & 148367720 \\
\hline MAY & 518649381 & 43367048 & 21730863 & 3217234 & 3331709520 \\
\hline JUN & 43872364 & 43372557 & 13403376 & 4093669 & 72749417 \\
\hline JUL & 15061956 & 9443960 & 29123540 & 4765700 & 97403422 \\
\hline AUG & 10745499 & 43918134 & 20571842 & 2858406 & 54024740 \\
\hline SEP & 31055691 & 20150434 & 3966706 & 6897065 & 85512669 \\
\hline OCT & 6136675 & 4387974 & 6767486 & 10770750 & 80214040 \\
\hline NOV & 16424561 & 12306168 & 3605193 & 30860459 & 137787282 \\
\hline DEC & 5838395 & 12496811 & 1241589 & 4357636 & 79203149 \\
\hline
\end{tabular}

All values are greater than zero indicating presence of trading for the shares of KCB within this period.

\section{APPENDIX 6:}

TABLE X: Turnover for east african breweries from shares for the year $2009-2013$ in KSH.

\begin{tabular}{|l|l|l|l|l|l|}
\hline MONTH & 2009 & 2010 & 2011 & 2012 & 2013 \\
\hline JAN & 456462305 & 4629179 & $57827475^{*}$ & 15273156 & 60558630 \\
\hline FEB & 14000968 & 9845272 & 228170700 & 18433014 & 96149482 \\
\hline MAR & 108458889 & 32040360 & 55053761 & 11714976 & 86315305 \\
\hline APR & 78230475 & 30749188 & 44099577 & 8507807 & 171045565 \\
\hline MAY & 42119583 & 40502995 & 33655937 & 33067468 & 66678263 \\
\hline JUN & 14083369 & 39176690 & 5991450 & 18107100 & 295773078 \\
\hline JUL & 10172851 & 7581238 & 7888605 & 108469564 & 37608452 \\
\hline AUG & 121598251 & 59206758 & 3609040 & 93887704 & 429389988 \\
\hline SEP & 34900943 & 26414646 & 2949602 & 108146238 & 205652636 \\
\hline OCT & 3955849 & 46838001 & 30125497 & 36685194 & 201641710 \\
\hline NOV & 12397185 & 45087524 & 11018748 & 98166600 & 212222050 \\
\hline DEC & 20424215 & 26285067 & 71302424 & 153152160 & 233933799 \\
\hline
\end{tabular}

This value is derived as follows: From Appendix 10 the row for EABL we have $771033 \mathrm{X} 75=57827475$ 